\title{
Digitization and technological innovations in tourism of the Rostov region (the case of mobile applications for smartphones)
}

\author{
Elena Shevchenko ${ }^{1 *}$, and Lyudmila Kazmina ${ }^{1}$ \\ ${ }^{1}$ Don State Technical University, Gagarina Sq., 1, Rostov-on-Don, 344000, Russia
}

\begin{abstract}
The article is concerned with basic concepts and areas of tourism digitization in the Rostov region. Examples of online-services, their functions and growth drivers are provided. Development trends of digital techniques in tourism of the region are detected. One of mobile applications is analyzed, inventions are provided for its improvement intended to develop tourism and to expand variety of leisure activities for local residents.
\end{abstract}

\section{Introduction}

One of the most pronounced tendencies in development of modern tourism is its digitization. This industry is distinct in continuous innovations. Innovations are muchneeded for the Russia's economy and for the tourism industry as well.

Digital techniques are a driver of fundamental changes in the tourism industry globally. The main trends in tourism are globalization and formation of the largest Internet-channels. Patterns of interaction between touristic service providers and consumers are changing. Exclusion of intermediaries, reduction of advertising costs, looking for the nearest ways to deliver services to end customers are observed. Digitization plays a key role in these processes.

The purpose of this article is to study processes of digitization and innovation in the tourism industry of the Rostov region.

The purpose of the study determines the following tasks:

- to study the directions of digitization and innovation in tourism of the Rostov region;

- to identify the factors, conditions and prerequisites for the use of mobile applications in tourism, to study the market of mobile touristic applications and consumer preferences on the territory of the Rostov region;

- to determine the vectors for further development of mobile applications in the tourism industry of the Rostov region and to develop practical recommendations on their enhancement.

\footnotetext{
* Corresponding author: epetrova21@mail.ru
} 


\section{Materials and methods}

This study is based on the papers of foreign and domestic scientists in the field of technological innovation in tourism, tourism digitization, as well as the use of mobile applications in the tourism sector. A review of modern scientific literature shows that the role of digitization is significant for tourism development, and its importance keeps growing.

The study is based on perspectives on tourism digitization provided by such scientists as Inta Egger, Sut Ieng Lei, Philipp Wassler, Philip Alford, Rosalind Jones [1, 2].

Issues on use of mobile applications for smartphones are hot. These claims find endorsement in the papers of such authors as Maria Teresa Cuomo, Debora Tortora, Pantea Foroudi, Alex Giordano, Giuseppe Festa, Gerardino Metallo [3]. It is noted that mobile applications in the field of tourism are most actively used by young people. That is why it is preferably to develop such applications exactly for young audience and the middle-aged group, (Huseyin Bicen, Saide Sadiko glu, 2016 [4]). The experience of the countries, which successfully use smartphone touristic applications (Meiliana Devita, Irmanti Mochamad, Rizal Hidayat, Nur Viani, Amalina Dewi Suryani, 2017 [5]) is taken into consideration. Mobile touristic applications are constantly upgraded, become more diversified and userfriendly. Comprehension and availability of smartphone applications have an impact on attraction of tourists to the tourist territories, for which they were developed (Chia-Chen Chen, Jia-Lun Tsai, 2019 [6]).

Mobile touristic applications for smartphones are a part of the overall scope of tourism innovations. This study presents experience of academic papers on innovation in tourism in general. They are represented in the papers of Vanda Veréb, António Azevedo, Ángela Martínez-Pérez, Dioni Elche, Pedro M.García-Villaverde 2019, [7, 8]. The present study used some provisions and the reserach methodology of Ingrid Kofler, Anja Marcher, Michael Volgger, 2018, Beatriz Casais, Juliana Fernandes, Mariana Sarmento, 2020 [9, 10].

Issues on tourism innovations with regard to virtual reality are described in the paper of Myung Ja Kim, Choong-Ki Lee, Michael W.Preis, 2020, to which the authors of the present article refer too [11]. It is noted that tourism innovations influence not only the direct attraction of tourists and better services, but also systems of management of the whole industry (Marcus Hansen, Anne-Mette Hjalager, Alan Fyall, Birgit Pikkemaat, Mike Peters, Bernhard Fabian Bichler 2019, Osnat Broshi-Chen, Yoel Mansfeld, 2021 [12-15].

Tourism in the Rostov region is the subject of the papers of such authors as L.N. Kazmina, V.S. Makarenko, V.V. Provotorina, T.N. Grigorenko, 2019 [16-18]. Some aspects of tourism (i.e. agritourism) are reflected in the papers of E.Shevchenko, A.Petrenko, G. Ekinil, 2020 [19-21]. When conducting the study, the authors relied on provisions of the papers of M.S. Giltsova, O.A. Mironova, A.V.Truhachev, Gorgadze, L., 2020 [22-24].

In the study, statistics, findings of surveys of couriers and touristic application developers were used. The following methods were used when conducting the study: a statistical analysis of information, a comparative analysis of mobile applications and other digital cervices, a spatial analysis of the territory, economic, chronological, predictive methods.

\section{Results}

Digital techniques have become ingrained in all spheres of human activities and in everyday lives as well. They make many areas of activities much easier. Moreover, their implementation requires transformations, qualitative reengineering of all processes. Some participants put digital resources to a good use and thus increase their stability on the 
tourism market, while others give their niches to companies that are able to navigate a changing economic backdrop. The sector of organized tourism undergoes significant changes caused by global digitization. Major global tour operators are the first to implement innovations in their production and promotion. Digitization is one of the most important conditions of competitiveness. Implementation of digital techniques provided for formation of global strategic alignments in the tourism industry. It would be impossible without booking systems and platforms for quick transfer of great deal of information.

In addition to organized tourists, this sector includes a large number of self-guided tourists, who carve out a significant niche in the industry. According to the Federal Agency of Tourism of Russia, more than $25 \%$ of tourists travel independently using, in particular, digital services. It is the category of travelers, for whom such technologies are of great relevance. The first digital platforms have been ticket and hotel booking systems, such as Booking, Airbnb and Aviasales, which are very popular today. It was a revolution in tourism development it its days. Today, there is a wide range of digital techniques for tourists. They become ingrained in our everyday lives and make tours easy. For the present moment, a variety of such services has grown significantly and includes the following types:

- mapping services, including geo information systems;

- traveler guides;

- audio guides;

- hotel and transport booking application;

- RAC;

- food, beverage and entertainment reference applications;

- weather reference applications;

- virtual tours and excursions services;

- services containing tourists' feedback;

- social networks;

- tour planners (flight and rout connections, etc.)

Official sites and mobile applications for booking additional services, such as RAC, electronic visa processing, policy, etc. are worth to be noted too. Today, such services are an integral part of any tours, even of short and quick ones. Airline companies establish their own companies and hotels. It allows them to develop their own digital systems for online organization of tours. It was called Dynamic Organization of Tours. It provides a means to pursue a flexible price policy, to exclude many intermediaries and to improve the competitiveness.

In the context of digital services in tourism, special attention should be paid to mobile applications of government agencies. Such applications are not commercial projects, but represent an important informational service for tourists. The Foreign Ministry's official mobile application Зарубежный помощник (Foreign Assistant) is a good example. This application contains all the necessary information for tourists. It is especially important in the period of the coronavirus pandemic, when biological safety becomes the key factor on journeys. This application offers latest information concerning issues on rules of traveling abroad, quarantine measures, etc.

In today's context, in addition to the digital systems mentioned above, voice-activated digital assistants get widespread. These are devices, which react on voice commands. They are offered both as integrated in mobile devices and as stand-alone devices. They make it possible to get a wide range of services - from medical advisements to food delivery. An increasing number of people trust such devices. The tourism industry is par for the course. One of the world's largest companies Amazon implements a special program for hotels, which allows to order room cleaning, to flip channels, or to control devices using voice. Another up-to-date example is Google's program for mobile devices - an assistant for travel 
arrangements. Based on general data (traveling time, country, season, transport, etc), this service advises, what to take for the journey. Alice made by Yandex can be called a voice service containing general information. It is useful for journeys, as it allows getting various information - names of plants, animals, description of sightseeing attractions, etc.

Digital services facilitate standard operations in tourism, i.e. to compare prices for tickets, flight connections, etc. Moreover, a so-called digital footprint is disclosed in modern mobile devices. Based on searches on phone or tablet, needs of a tourist are tracked. Then ready-made solutions in the form of tours, excursions and other services are offered on the basis of these searches.

Prospects of global tourism are closely connected to digital techniques. They enter in all spheres of life. So, some specialists assume that there will be no longer any necessity for travel agencies with real-world consultees, as most of consumers of tourist services will leave for cyberdomain. There can be a large role for chat bots, which allow making it possible to cut concerns on the staff, operate 24/7 and to gain time. For example, Mindsay chat bot, which automates up to $90 \%$ of client requests and operates in more than 100 world's languages. Moreover, the service is integrated with many third-party applications, i.e. for hotel and tickets booking. Various Internet channels, having a wide customer base, expand their range of services by adding tourist services, even if the specifics of the channel is not initially related to tourism. Often it ousts traditional tour operators from the tourism market.

Virtual reality (VR), which is widely used in promotion of touristic products, should be also mentioned as an innovation in tourism. This technology helps to create virtual presentations. They can be viewed by means of VR-helmet and VR-glasses. They provide full immersion into the atmosphere of the presented object. In such a way, demonstration of tours, excursions around cities, natural sites, museums, etc. are conducted. This method proved its effectiveness. For example, viewing of a tour presentation by means of VRtechnology increases the volume of bookings of this direction. Success of virtual tours is explained by the fact that a touristic product is unperceivable. It can not be tried before purchase that is why it is the sphere, where visualization of a service is very important. Such methods are widely used in tourism of the USA and of many European countries. The largest tour operator using such services is Travel World VR. In Russia, this technology is not widely used. But the Ermitazh, the Tretyakov Gallery and some other objects have virtual tours. Effective application of such a resource as VR-technology for the tourism development in Russia requires a large number of demonstration videos on various touristic destinations. This approach is especially relevant for popularization of inbound tourism.

\section{Discussion}

In the present article, special attention is paid to such a type of digital services as mobile applications for smartphones. Mobile applications are special services to be used in mobile devices - telephones and tablets. They are not innovations any more, as they are widely used. But their constant updating, extending of options for the existing services should be noted as direct innovations. Mobile applications are very important for self-guided tourists. Indeed, in contrast to organized travelers, whose route is planned by a tour operator and controlled by a guide, self-guided tourists need more information. Therefore, the popularity of mobile applications will only grow, as self-guided tourism becomes ever more popular.

Studies show that there is a positive trend in this area. This is expressed by the following:

- an increase in the number of self-bookings through mobile applications;

- an increase in the number of various mobile applications;

- enhancement of mobile applications. 
Such a rapid growth in the popularity of mobile touristic applications is stimulated by the following factors:

- an increase in the number of mobile devices among the population. In 2020 in Russia, more than 80 million people (with a population of 146.7 million people) have smartphones, i.e. almost each adult has at least one mobile device;

- availability and relative cheapness of the mobile Internet. The cost of $1 \mathrm{~GB}$ of traffic in Russia is about 66 rubles. As a comparison, in Switzerland the same traffic volume costs 1117 rubles.

- easy of use of mobile services;

- binding to payment systems that allow you to pay for services. The international payment systems "Visa", "MasterCard" and the Russian national system "Mir" are linked to mobile applications.

It should be noted that individualizing of leisure and more frequent tourists' use of Internet-services are important trends of today's tourism. Traditional air ticket offices are not popular any more as more than $80 \%$ of consumers buy tickets online. The same holds for buying tours from traditional travel agencies.

The advantages of using mobile phone applications in the tourism industry are as follows:

- low cost, and often free installation;

- simple search for download in APP Store or Google Play systems;

- ease of use;

- a variety of applications;

- cheaper cost of excursions compared to organized excursions conducted by a real guide.

Despite a rapid growth of the mobile applications market, it should be noted that it is weakly saturated in Russia. At the same time, there are no mechanisms for regulating this area. There are no mandatory standards for such services in Russia yet. The voluntary standard "Russian quality system. Comparative tests of mobile applications for smartphones" is worth special attention. It provides a list of general requirements for mobile applications. This standard has the PNST 277-2018 (National prestandard 2772018) marking. It was developed in 2018.

Mobile applications in the sphere of tourism in Russia have great prospects, although the level of their use is falling behind many foreign countries.

The Rostov region is considered as an example of the development of regional tourism. This is a region in the South of Russia with great tourism potential, annually hosting up to 1.5 million tourists. The territory of the Rostov region is distinguished by a wide range of natural and cultural and historical resources, developed tourist infrastructure, and a favorable transit position. Precious little mobile applications for tourists have been developed for this territory.

Most important services in the sphere of tourism of the Rostov region is, first of all, the official site of the regional administration dealing with tourism https://visitdon.ru/ It is informative, rich and contains comprehensive information for tourists. For example, there is a description of the region, main attractions, travel agencies, visa centers, an event calendar, information for representatives of the travel industry, etc. on site. Another digital technology in tourism of the Rostov region was the program of the region VR presentation in 2019. It was presented at the regional tourism forum and immediately gained great popularity. The technology is used at national and regional tourism exhibitions and attracts attention of potential tourists, as well as of business partners in various areas of the tourism industry. 
An important service for both tourists and local residents is Yandex. Maps and Transport Here you can track movement of public transport in real time, plan the best routes. Moreover, the application contains information on catering establishments, ATMs, pharmacies, and entertainment facilities. The SberFood application makes it possible to book a table in restaurants, pay a bill contactlessly, and tip without cash.

An important role in the development of tourism in the Rostov region is played by the systems for booking hotels and transport tickets, which have already become popular. And, of course, mobile applications for tourists are noteworthy. These include Trivago, Booking, Kayak, Airbnb, Yandex.Taxi and others. In the list of applications for excursions, the TopTripTip should be noted. This application was developed within the framework of the All-Russian tourist project "Traveling in Russia" with the assistance of the Ministry of Culture and the Federal Agency for Tourism of Russia. It is a guide to various cities and districts of the Rostov region. It contains descriptions and photographs of more than 50 attractions, characteristics of tourist routes and interesting events taking place in the region. It is noteworthy that the application has Russian and English versions.

In addition, the tourist application "REQUEST" deserves attention. Its database contains a number of audio tours; the tourist map includes 220 objects. Most of the routes pass through the historical parts of Rostov-on-Don, which are full with tourist attractions. There are excursions to other cities of the Rostov region.

The application has a high-quality, user-friendly, informative design and contains many photos and panoramas. All points of the excursion route are geolocated, i.e. they have geotagging. When the geolocation function is on in the phone or tablet, the application understands where the tourist is located and shows the direction to go in accordance with the selected excursion route.

The number of not only Russian-speaking users, applications, but also foreign ones is increasing. This is shown in Fig. 1.

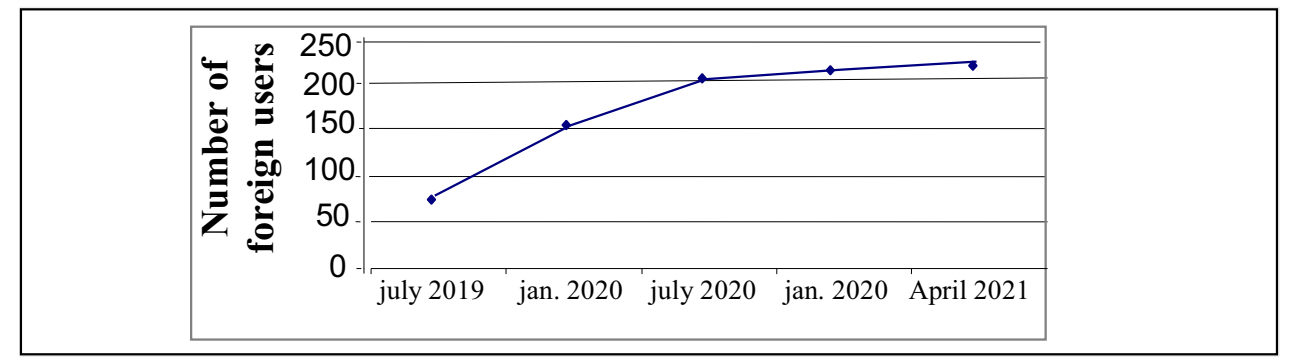

Fig. 1. Growth rate of foreign users of the REQUEST application.

Opinions of consumers of the application services researched by studying reviews showed that there is a need to expand excursion routes. Survey results are shown in Fig. 2. 


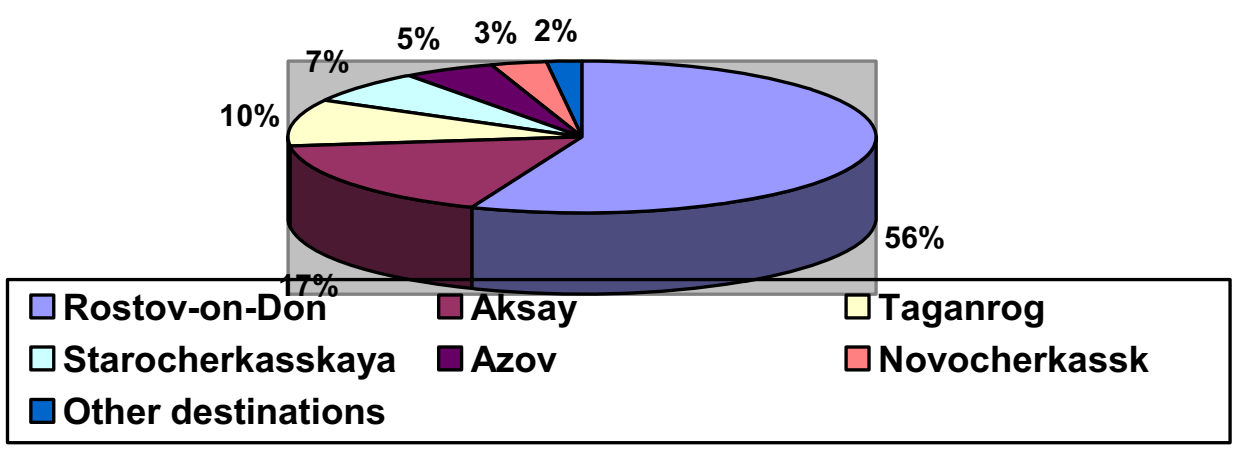

Fig. 2. The need for excursion routes in the REQUEST application based on consumer feedbacks.

A shift in demand requires developers to update information resources constantly. In the light of the above, the authors of the article developed new travel offers for the REQUEST mobile application.

It is proposed to implement such a service as TeleTour. It is a telephone tour. According to it, the guides can conduct a virtual tour along the desired route by phone. The route and time of the excursion must be planned in advance. Modern technologies of video calls by mobile phones or tablets make it possible to conduct such tours. This is particularly important in a period of increased biological hazard associated with covid-19. Reducing personal contact has a beneficial effect on safety of tourists. At the same time, the possibility to obtain tourist services remains. Therefore, the TeleTour service seems promising and interesting. Moreover, it is proposed to supplement the content of the application with quests for tourists to expand its features. Quests, including virtual ones, are gaining popularity. This service is oriented more to a youth audience, i.e. exactly the age group that is an active user of mobile applications (including REQUEST). Updating of the application services with various quests will promote activation of domestic tourism.

Quests can be conducted on streets or in special rooms (quest rooms or derelict buildings). There can be all types of quest topics - from scientific and educational to adventure.

For the REQUEST mobile application it is proposed to develop a series of thematic quests intended to attract tourists and sightseers of different age categories and interests. However, specificity of quests is largely focused on a more youthful audience (16-35 years old). Nevertheless, quests conducted without a real organizer, but only using a mobile application, can be universal. Quests' orientation should be compliant with the specifics of the territory. So, for Rostov-on-Don, a topic associated with the history of merchants, the Cossackdom, the civil and the Great Patriotic War seems to be optimal.

The course of a quest involves moving between the planned points of the route, mission completion, guessing with the use of reference points. All points of the route are interconnected by subject and timed. As a result, tourists get new knowledge and impressions. Local residents may also be interested in such a service, because they will be able to see familiar places from an unusual point of view.

The results of the cooperation of the authors of the article and the developers of the REQUEST mobile application are presented in the form of a project of the TeleTour telephone tour, as well as a series of quests around Rostov-on-Don on various topics. Routes and descriptions of tourist services are developed by the study authors; technical support of implementation of the results is a function of the digital service developers. 


\section{Conclusions}

Based on the results of the conducted study a number of conclusions can be made:

1. All over the world, there is an intensification and individualization of self-guided tourism. As a result, there is a growing need for digital services to facilitate travel arrangements. The list of digital technologies in tourism is expanding.

2. There is a replacement of real-world travel agencies and even tour operators from the tourist market by online services providing for dynamic formation of tours oriented to the personal needs of tourists.

3. In the Rostov region, the digitalization of the tourist market is in its infancy. There are positive trends in this area. There is a need to increase the number of digital services and to enhance the existing mobile applications. Active promotion of both tourism in the region through the activation of digital services and the services themselves is required.

4. The innovative services (quests and the TeleTour telephone excursions) codeveloped by the authors of the article and the owner of the REQUEST mobile application is being practically introduced into the tourism practice of the Rostov region. Expansion of the age range of mobile application users from 18-35 years old to 16-50 years, an increase in the number of downloads, as well as of repeated calls to the application services are noted. New services within the application receive positive feedback, which indicates the success of this project.

\section{References}

1. I. Egger, S. I. Lei, P. Wassler, Tourism Management, 79, Article 104098 (2020), https://doi.org/10.1016/j.tourman.2020.104098

2. P. Alford, R. Jones, Tourism Management, 81, 104139, (2020), https://doi.org/10.1016/j.tourman.2020.104139

3. M. T. Cuomo, D. Tortora, P. Foroudi, et al., Technological Forecasting and Social Change, 162, 120345 (2021), https://doi.org/10.1016/j.techfore.2020.120345

4. H. Bicen, S. S. Glu, Procedia Economics and Finance, 39, 270-274 (2016)

5. M. Devita, I. Mochamad, R. Hidayat, et al., Procedia Computer Science, 116, 556-563 (2017), https://doi.org/10.1016/j.procs.2017.10.059

6. C.-C. Chen, J.-L. Tsai, Future Generation Computer Systems, 96, 628-638 (2019), https://doi.org/10.1016/j.future.2017.02.028

7. V. Veréb, A. Azevedo, Journal of Hospitality and Tourism Management, 41, 208-218 (2019), https://doi.org/10.1016/j.jhtm.2019.10.003

8. Á. Martínez-Pérez, D. Elche, P. M.García-Villaverde, Journal of Destination $\begin{array}{lllll}\text { Marketing \& } \quad \text { Management, } & \text { 11, 2019), }\end{array}$ https://doi.org/10.1016/j.jdmm.2018.12.002

9. I. Kofler, A. Marcher, M. Volgger, H. Pechlaner, Journal of Hospitality and Tourism Management, 37, 68-75 (2018), https://doi.org/10.1016/j.jhtm.2018.09.004

10. B. Casais, J. Fernandes, M. Sarmento, Journal of Hospitality and Tourism Management, 42, 51-57 (2020), https://doi.org/10.1016/j.jhtm.2019.11.010

11. M. J. Kim, C.-K. Lee, M. W.Preis, Telematics and Informatics, 49, 101349 (2020), https://doi.org/10.1016/j.tele.2020.101349 
12. M. Hansen, A.-M. Hjalager, A. Fyall, Journal of Outdoor Recreation and Tourism, 28, 100253 (2019), https://doi.org/10.1016/j.jort.2019.100253

13. B. Pikkemaat, M. Peters, B. F. Bichler, Journal of Hospitality and Tourism Management, 41, 184-196, (2019)

14. O. Broshi-Chen, Y. Mansfeld, Journal of Hospitality and Tourism Management, 46, 272-283 (2021), https://doi.org/10.1016/j.jhtm.2021.01.003

15. S. Karampela, D. Kavroudakis, T. Kizos, Current Issues in Tourism, 22 (12), 14601479 (2019)

16. V. Provotorina, L. Kazmina, A. Petrenko, V. Makarenko, Lecture Notes in Civil Engineering, 130, 20-32 (2021)

17. L. Kazmina, V. Makarenko, V. Provotorina, E. Shevchenko, E3S Web of Conferences, 175, $10001(2020)$

18. V. Provotorina, L. Kazmina, A. Petrenko, G Ekinil, E3S Web of Conferences, 175, $10002(2020)$

19. G. Ekinil, V. Provotorina, A. Petrenko, L. Gorgadze, E3S Web of Conferences, 217, 05006 (2020)

20. M. S. Giltsova, O. A. Mironova, Modern fundamental and applied research, 1(32), 7075 (2019)

21. A. V. Truhachev, Service in Russia and Abroad, 10(3), 260-275 (2016), doi: $10.12737 / 20116$

22. G. Ekinil, L. Gorgadze, V. Provotorina, A. Petrenko, IOP Conference Series: Materials Science and Engineering, 1001(1), 012118 (2020), https://doi.org/10.1088/1757899X/1001/1/012118

23. L. Kazmina, V. Makarenko, V. Provotorina, E. Shevchenko, E3S Web of Conferences, 210, 12002 (2020)

24. L. N. Kazmina, V. S. Makarenko, V. V. Provotorina, T. N. Grigorenko, International Journal of Economics and Business Administration, 7, 510-520 (2019), doi: $10.35808 / \mathrm{ijeba} / 297$ 